\title{
Case Study: Accelerating Process Improvement by Integrating the TSP and CMMI
}

Daniel S. Wall

James McHale

Marsha Pomeroy-Huff

December 2005

SPECIAL REPORT

CMU/SEI-2005-SR-012

ESC-SR-2005-012 

= CarnegieMellon

느 Software Engineering Institute

Pittsburgh, PA 15213-3890

\section{Case Study: Accelerating Process Improvement by Integrating the TSP and CMMI}

CMU/SEI-2005-SR-012

Daniel S. Wall

James McHale

Marsha Pomeroy-Huff

December 2005

Software Engineering Process Management

Unlimited distribution subject to the copyright. 
This report was prepared for the U.S. Naval Air Systems Command.

SEI Administrative Agent

ESC/XPK

5 Eglin Street

Hanscom AFB, MA 01731-2100

The ideas and findings in this report should not be construed as an official DoD position. It is published in the interest of scientific and technical information exchange.

This work is sponsored by the U.S. Department of Defense. The Software Engineering Institute is a federally funded research and development center sponsored by the U.S. Department of Defense.

Copyright 2006 Carnegie Mellon University.

NO WARRANTY

THIS CARNEGIE MELLON UNIVERSITY AND SOFTWARE ENGINEERING INSTITUTE MATERIAL IS FURNISHED ON AN "AS-IS" BASIS. CARNEGIE MELLON UNIVERSITY MAKES NO WARRANTIES OF ANY KIND, EITHER EXPRESSED OR IMPLIED, AS TO ANY MATTER INCLUDING, BUT NOT LIMITED TO, WARRANTY OF FITNESS FOR PURPOSE OR MERCHANTABILITY, EXCLUSIVITY, OR RESULTS OBTAINED FROM USE OF THE MATERIAL. CARNEGIE MELLON UNIVERSITY DOES NOT MAKE ANY WARRANTY OF ANY KIND WITH RESPECT TO FREEDOM FROM PATENT, TRADEMARK, OR COPYRIGHT INFRINGEMENT.

Use of any trademarks in this report is not intended in any way to infringe on the rights of the trademark holder.

Internal use. Permission to reproduce this document and to prepare derivative works from this document for internal use is granted, provided the copyright and "No Warranty" statements are included with all reproductions and derivative works. 


\section{Table of Contents}

Acknowlegements................................................................................... vii

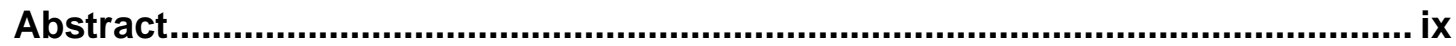

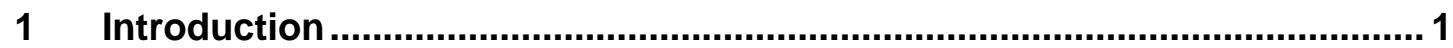

2 The CMMI Framework and PSP and TSP Methodologies............................. 3

2.1 The CMMI Framework ...................................................................... 3

2.1.1 Average Time Between Maturity Levels ................................... 3

2.2 The PSP and TSP Methodologies ................................................. 4

2.2.1 The PSP and TSP Introduction Strategy ............................... 4

2.2.2 The TSP and CMMI are Complementary ................................ 5

3 TSP Accelerates Process Improvement in Two NAVAIR Organizations ...... 9

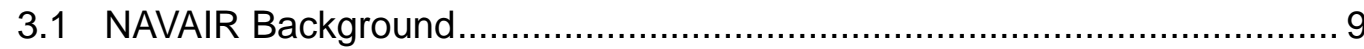

3.2 P-3C Maritime Surveillance Aircraft Software Support Activity (NAVAIR

Pax River, Maryland) ................................................................... 10

3.2.1 Organization Background .................................................. 10

3.2.2 Process Improvement Approach........................................... 11

3.2.3 Process Improvement Timeline .............................................. 14

3.2.4 Continuing Process Improvement in the P-3C SSA Organization 14

3.3 AV-8B Joint System Support Activity (China Lake, California)................. 15

3.3.1 Organization Background ................................................ 15

3.3.2 Process Improvement Approach ............................................. 15

3.3.3 Process Improvement Timeline ............................................ 18

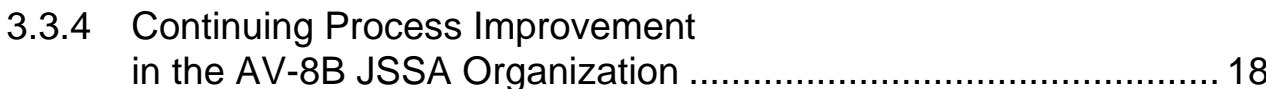

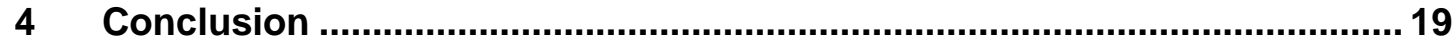

4.1 Components Required for Successful Change.................................... 19

4.2 Key Factors in NAVAIR's Process Improvement Success ...................... 20

4.3 Conclusion ................................................................................ 22

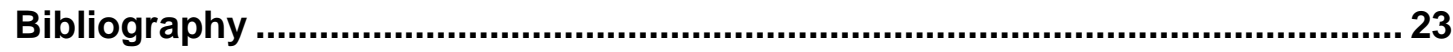




\section{List of Figures}

Figure 1: Time Required to Move up Maturity Levels .................................... 4

Figure 2: $\quad$ The CMMI Framework, TSP, and PSP are Complementary .................. 6

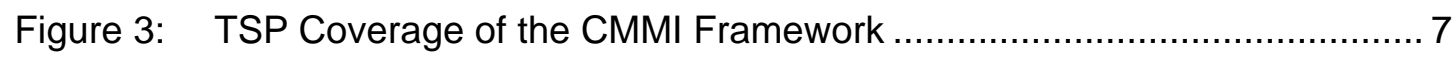

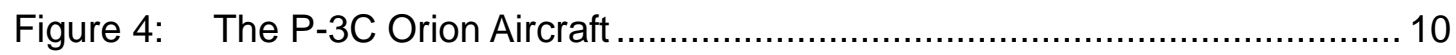

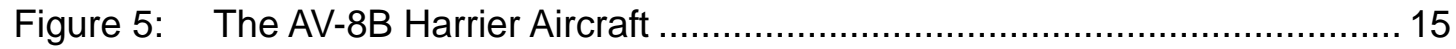




\section{List of Tables}

Table 1: $\quad$ P-3C Process Improvement Results ................................................ 13 


\section{Acknowlegements}

The authors would like to thank several individuals from NAVAIR for contributing their information and insight into the TSP-based SW-CMM improvement effort. These are Jeff Schwalb, Lisa Pracchia, Julia Switzer, and Katie Smith. Other individuals also contributed to reviewing the content and clarity of the report, and we would like to thank them for their time and assistance: Susan Kushner, Jim Over, and Bill Peterson. In particular, we would like to thank our editor, Claire Dixon, for her patience and diligence in the face of numerous revisions and rewrites, and for her excellent work in blending the combined efforts of the several authors into a coherent whole. 


\section{Abstract}

This report describes how two U.S. Naval Air Systems Command (NAVAIR) organizations integrated the use of the Software Engineering Institute's (SEI) Team Software Process ${ }^{\text {SM }}$ methodology and the Capability Maturity Modeling ${ }^{\circledR}$ framework to progress from Maturity Level 1 to Maturity Level 4 in 30 months. This is less than half of the average time it has taken other organizations to accomplish the same maturity level progression. This case study describes the process improvement efforts of both NAVAIR divisions and how they integrated the two SEI technologies to accelerate process improvement within their organizations. Finally, the report presents the key factors that allowed NAVAIR to achieve these rapid results. 



\section{Introduction}

Most software projects are delivered late, over budget, with less functionality than expected, and with quality problems. According to a Standish Group International CHAOS study [Standish 01], only 28 percent of all software projects finish on schedule, within budget, and contain all of the features and functions as originally specified. To help address these problems, many organizations have implemented process improvement programs based on the Capability Maturity Model for Software (SW-CMM ${ }^{\circledR}$ ) and the Capability Maturity Model Integration $\left(\mathrm{CMMI}^{\circledR}\right)$ frameworks. Even with SW-CMM or CMMI, the road to success often proves to be difficult. As a result, it is not uncommon to hear comments such as the improvement efforts take too long, do not persist within the organization, or do not yield measurable results. These software process improvement failures are generally due to the fact that, "too often, programs [lack] well-thought-out, disciplined program management and/or software development processes" [NAVAIR 02], which are crucial elements for the successful implementation of improvement programs based on the SW-CMM or CMMI frameworks.

This report outlines how two U.S. Naval Air Systems Command (NAVAIR) organizations integrated a pair of complementary process improvement technologies, SW-CMM and Team Software Process (TSP), to accelerate implementation of a solution to address their process improvement problems. The information contained in this report should prove to be useful for Software Engineering Process Groups (SEPGs), Engineering Process Group (EPG) members, Team Software Process ${ }^{\mathrm{SM}}\left(\mathrm{TSP}^{\mathrm{SM}}\right)$ coaches, process professionals, process managers, project leaders, and organizational managers who are interested in addressing cost, scheduling, and quality problems. The report assumes the reader has some general familiarity with process improvement activities, but may not be familiar with the details of the SW-CMM, CMMI, or TSP technologies. Readers who are unfamiliar with these technologies can review the materials listed in the bibliography.

Section 2 of this report provides background information about the process improvement methodologies used by NAVAIR: Capability Maturity Modeling (CMM), Personal Software Process $^{\mathrm{SM}}$ (PSP $^{\mathrm{SM}}$ ), and TSP. Section 3 presents information about the two NAVAIR organizations that participated in this case study and describes the key components and activities used to achieve rapid results. Based on these data, the conclusion of this report in Section 4 summarizes the common elements that helped the NAVAIR organizations to achieve lasting process improvement success.

( $\quad$ CMM and CMMI are registered in the U.S. Patent and Trademark Office by Carnegie Mellon University.

SM Team Software Process, TSP, Personal Software Process, and PSP are service marks of Carnegie Mellon University. 


\section{The CMMI Framework and PSP and TSP Methodologies}

\subsection{The CMMI Framework}

The CMMI framework is a reference model consisting of best practice descriptions for a broad range of engineering activities, covering the entire product life cycle from requirements definition through delivery and maintenance. It succeeds the Systems Engineering Capability Model (SECM) from the Electronics Industries Alliance, the Integrated Product Development Capability Maturity Model (IPD-CMM), and the SW-CMM, which was originated by the Carnegie Mellon ${ }^{\circledR}$ Software Engineering Institute (SEI) [Chrissis 03]. Because many process improvement models focus on a specific part of an organization's operations and do not take a systemic approach to the problems that most organizations face, such models tend to perpetuate the barriers to improvement that exist in most organizations. The CMMI framework builds on the SW-CMM concepts to provide a mechanism for process improvement that helps organizations to avoid or eliminate these barriers by integrating models that transcend disciplines. As a descriptive model, CMMI is well suited for organizations that are seeking to quantify their capabilities within the scope of software, systems, or product engineering by participating in an appraisal. It is also instrumental in guiding the broad direction of process improvement efforts in each area of expertise.

Like the SW-CMM model, the CMMI framework is based on the premise that process improvement is based on small, evolutionary steps rather than large-scale, sweeping changes [Paulk 93]. The SW-CMM and CMMI (staged) frameworks provide a foundation for gradual improvement by defining five maturity levels that set forth a measurable set of criteria for assessing an organization's software process maturity and for evaluating its software capability. Each of the five levels is composed of a set of process areas with component goals, that, when satisfied, provide significant improvement in a particular area of the software process.

\subsubsection{Average Time Between Maturity Levels}

Because the CMMI has only recently replaced the SW-CMM, there currently is insufficient statistically valid data to report on the average time taken by an organization to transition from one maturity level to the next when using the CMMI framework; however, preliminary

(B) Carnegie Mellon is registered in the U.S. Patent and Trademark Office by Carnegie Mellon University. 
evidence suggests that the time for transitions between CMMI maturity levels is likely to be similar to that of organizations that used SW-CMM. SEI data show that the mean time required for such organizations to progress from Maturity Level 2 (ML2) to Maturity Level 3 (ML3) was 19 months, and the mean time to progress from ML3 to Maturity Level 4 (ML4) was 25 months. Figure 1 depicts the average time that organizations need to move from one maturity level to the next with SW-CMM [SEI 04].

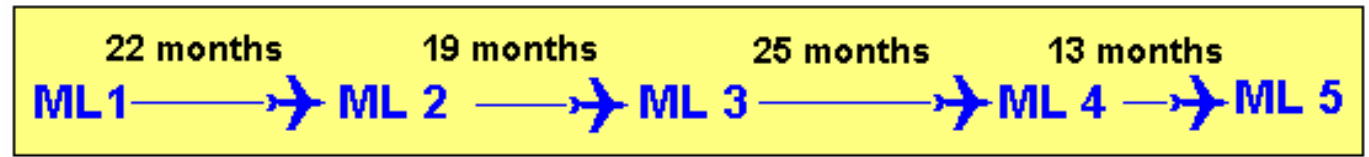

Figure 1: Time Required to Move up Maturity Levels

\subsection{The PSP and TSP Methodologies}

Historically, SW-CMM principles were used primarily by large organizations. Because of these successful implementations, small organizations and separate units of large organizations wanted to know how they could tailor the SW-CMM for use in their environments. Could software development teams and individuals apply similar principles to improve their work? Watts S. Humphrey, a founder of the process improvement initiative at the SEI, decided to apply SW-CMM principles to the development of module-sized software programs, both to see whether this approach could work at the individual level and to determine whether software engineers could be convinced to adopt different practices for developing software modules. Humphrey's research evolved into the Personal Software Process (PSP). In developing the PSP methodologies, he used the software SW-CMM practices up through Maturity Level 5 that made sense for individual practitioners.

PSP process provides engineers with a structured framework for doing software work. It consists of a set of methods, forms, scripts, measures, and standards that show software engineers how to use a disciplined process to plan, measure, and manage their work.

After developing PSP, the next milestone in software process improvement was the introduction of the Team Software Process (TSP). TSP uses the principles and methods of PSP to provide a context for performing disciplined, team-oriented engineering work. The principal motivator for the development of the TSP was the conviction that engineering teams can do extraordinary work, but only if such teams are properly formed, suitably trained, staffed with skilled members, and effectively led. The objective of TSP is to provide a framework for building and guiding such teams.

\subsubsection{The PSP and TSP Introduction Strategy}

The SEI has developed a strategy for introducing the PSP and TSP into an organization. This strategy parallels many aspects of the SW-CMM introduction strategy and, as will be described in Section 3 of this report, the SEI introduction strategy was followed closely by the 
organizations at NAVAIR. The introduction strategy involves the following overlapping steps.

1. Identify the key projects for the initial introduction.

2. Hold an executive strategy seminar with the key stakeholders (1 day) and a transition planning session (0.5 day).

3. Identify two to four projects to pilot the process. Use the following guidelines when selecting pilot projects.

- 3 to 15 people

- 4- to 18-month schedule

- representative of the organization's primary work

- software-intensive new development or maintenance

- $\quad$ willing team members and managers

4. Train affected managers (three days), engineers (two weeks), and support personnel (two days).

5. Conduct pilot projects and evaluate the results.

6. Train and authorize an internal PSP/TSP transition team.

7. Define the introduction goals and responsibilities.

8. Designate a team to plan and initiate a broad rollout.

9. Work project by project and launch each one by using TSP.

10. Build an experience base and train managers, engineers, and other support personnel as needed.

11. Repeat the introduction steps across the organization.

Using this strategy, a 200-person software organization can achieve organization-wide use of TSP within 24 to 30 months. Training additional TSP instructors and coaches can increase this rate of adoption.

\subsubsection{The TSP and CMMI are Complementary}

When adopting a particular SEI improvement technology, many organizations mistakenly view implementation of this technology as a stand-alone effort. However, software engineering is a rich and varied field and, as demonstrated by many other fields of engineering and science, there are often important synergistic benefits between seemingly unrelated technical disciplines [McHale 05]. Therefore, adoption of TSP and CMMI should not be seen as an “either-or” choice, since TSP and CMMI are designed to work together. Much evidence suggests that the two technologies are most effective when introduced together.

The CMMI framework provides top-down guidance for what organizations should do to improve processes, while TSP and PSP provide team- and individual-oriented principles for how to implement most of the CMMI process areas. As shown in Figure 2, the CMMI framework 
provides the overall improvement structure needed for effective engineering work [Chrissis 03]. The TSP methodology enables engineering teams to more effectively develop and support software-intensive systems. The PSP provides the discipline that engineers need to consistently use a defined, planned, and measured process [Humphrey 96].

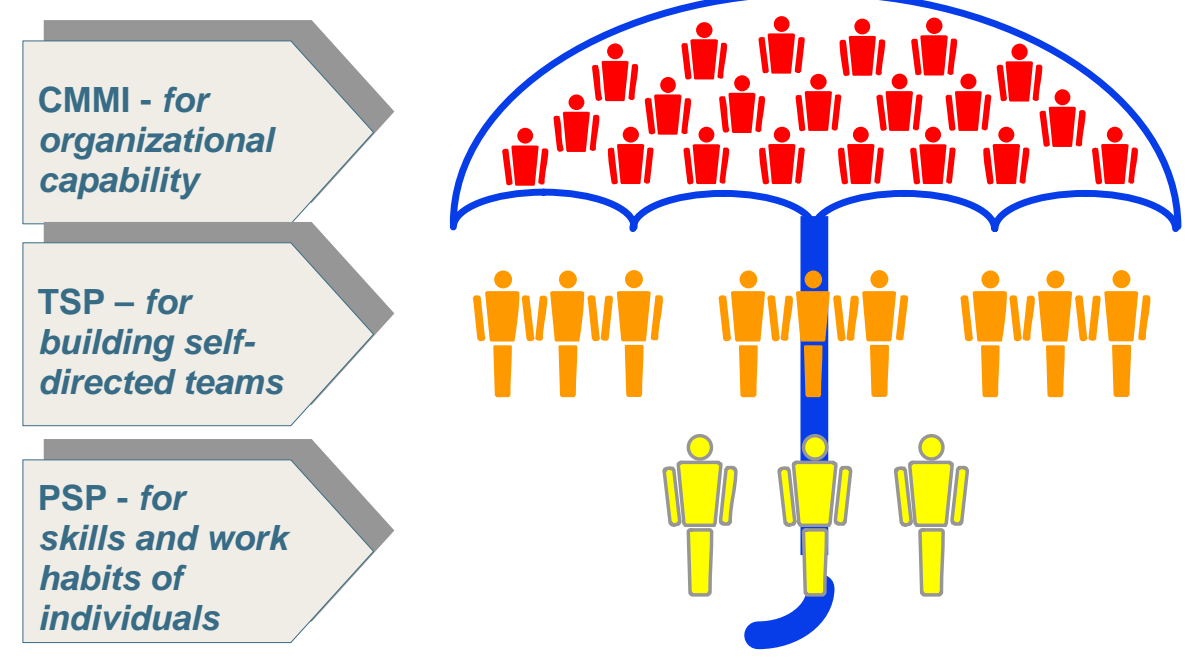

Figure 2: $\quad$ The CMMI Framework, TSP, and PSP are Complementary

TSP links the principles of integrated product teams with PSP and CMMI methods to produce effective teams. In essence, CMMI and PSP provide the organizational context and individual skills for effective engineering, while TSP guides teams in actually doing the work. Thus, TSP capitalizes on the preparation provided by PSP training and the CMMI framework, while also providing explicit guidance on how to do the work.

A growing body of evidence shows that TSP addresses key goals of both SW-CMM and CMMI, namely, delivering high-quality software, on schedule, and within cost [McAndrews 00, Davis 03]. In addition, TSP processes have been shown to correspond closely to CMMI practices [McHale 05]. TSP is also effective in helping real organizations to accelerate their achievement of high maturity [Hefley 02, Pracchia 04, Switzer 04]. Figure 3 shows TSP coverage of the CMMI framework. 


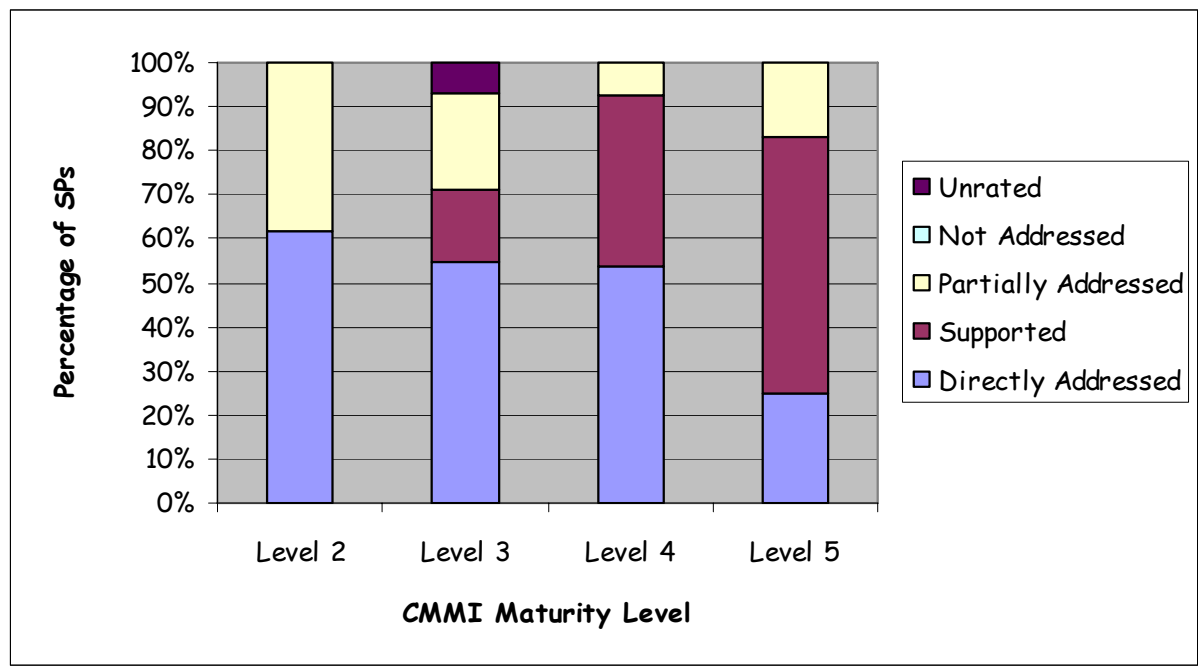

Figure 3: TSP Coverage of the CMMI Framework 


\section{TSP Accelerates Process Improvement in Two NAVAIR Organizations}

\subsection{NAVAIR Background}

The U.S. Naval Air Systems Command (NAVAIR) develops, acquires, and supports the aircraft and related weapons systems used by the U.S. Navy and Marine Corps. While NAVAIR has sites across the country, this case study focuses on two projects at different sites, the P3-C organization at the Naval Air Station Patuxent River, Maryland, and the AV-8 organization at China Lake, California.

In 1998, a Business Process Reengineering (BPR) team was assembled to make recommendations for improving software engineering practices across NAVAIR's field activities. After studying various organizations around the country and analyzing the collected data, the BPR group recommended that NAVAIR use the SW-CMM as a major tool for achieving software process improvement. One BPR group member, Jeff Schwalb of the Software Leadership Team (SLT), had previous software process improvement experience and was an authorized PSP instructor. At Schwalb's urging, Watts Humphrey briefed the SLT on the PSP and TSP, and after the briefing, the team understood that PSP and TSP methods were ways to quickly implement SW-CMM-based process improvement. Based in part on the early results from these efforts, NAVAIRINST 5234.2 policy was created, which included the following recommendations [NAVAIR 02].

“a. Programs and competencies engaged in systems software acquisition, development, and/or life cycle support should initiate process improvement using the $\mathrm{CMMI}^{\mathrm{SM}}-\mathrm{SE} / \mathrm{SW} / \mathrm{A}$.

b. Programs and competencies with defined and repeatable processes in systems software acquisition, development, and/or life cycle support should continue with their existing processes and transition to the $\mathrm{CMMI}^{\mathrm{SM}}$-SE/SW/A.

c. Programs engaged in organic software development should use the Personal Software Process and Team Software Process (PSP/TSP) methodologies for personnel training, project initiation and execution in conjunction with using the CMMI framework.”

After this policy was issued, both NAVAIR organizations continued to use PSP/TSP in conjunction with SW-CMM, with the goal of phasing in a gradual transition to the CMMI 
framework. The details of each organization's results of their PSP/TSP and SW-CMM implementation are documented in the following sections of this report.

\section{2 $\quad$ P-3C Maritime Surveillance Aircraft Software Support Activity (NAVAIR Pax River, Maryland)}

This section describes the background and approach of the P-3C Maritime Surveillance Aircraft (MSA) Software Support Activity (SSA) organization, which used TSP to decrease the amount of time required to progress between SW-CMM maturity levels.

\subsubsection{Organization Background}

The P-3C SSA organization is located at Naval Air Station Patuxent River, Maryland. It provides software support for the P-3C Orion aircraft, shown in Figure 4. The P-3C was originally designed as a land-based, long-range, anti-submarine warfare patrol aircraft, but today is used mostly for battlespace surveillance over both land and sea.

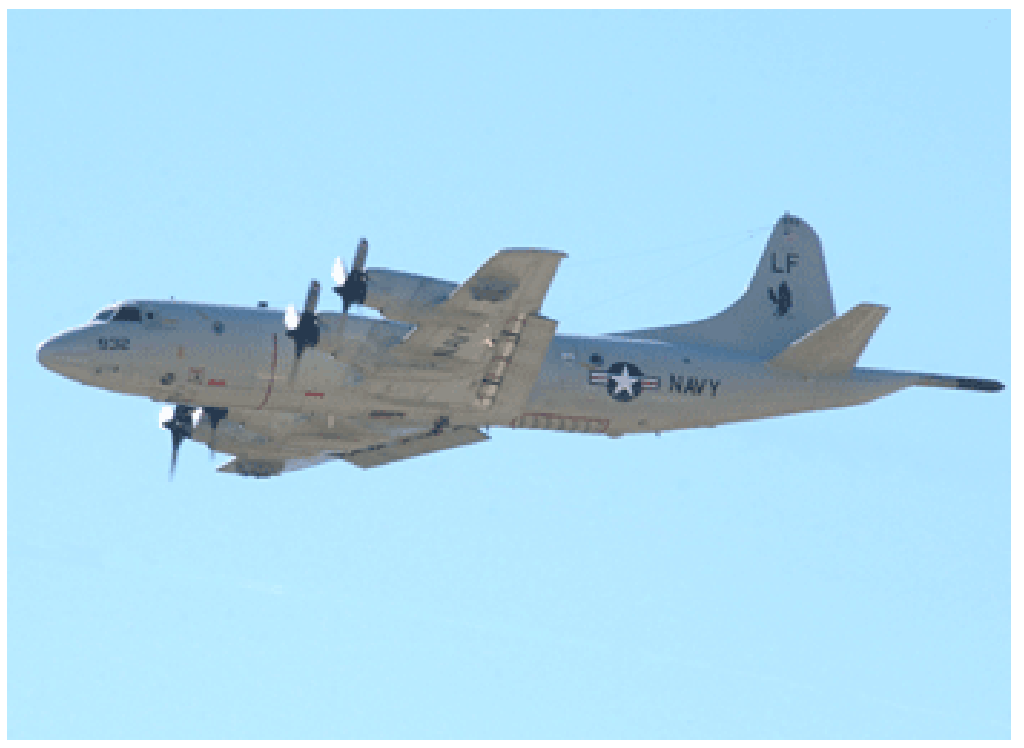

Figure 4: The P-3C Orion Aircraft

In May 2004, the P-3C SSA organization achieved SW-CMM Maturity Level 4 as determined by a CMM-Based Assessment for Internal Process Improvement (CBA-IPI). They accomplished this feat in just 27 months. According to SEI data, an organization starting at Maturity Level 1 can take almost six years to reach Maturity Level 4 (as previously shown in Figure 1). 


\subsubsection{Process Improvement Approach}

Based on the recommendation from the BRP and the realization that the organization needed to improve its processes, NAVAIR formed an Integrated Program Leadership Team (IPLT) in April 2001.

The IPLT participated in "High-Performance Organization (HPO)” workshops, during which the team documented its vision, values, and leadership philosophy and conducted a strategic customer-value analysis to ensure that the goals of the organization aligned with the needs of its sponsors. During these workshops, the leadership team realized that it had a real business need for developing a set of organizational process improvement goals. These goals were to

- positively affect cost, schedule, quality

- pursue credentials as evidence of strong business practices

- improve the work environment

- apply HPO principles to improve MSA SSA leadership philosophy, culture, and business processes

- $\quad$ satisfy NAVAIRINST 5234.2, which requires software-intensive programs to initiate process improvement practices [NAVAIR 04]

Before starting its improvement efforts, the IPLT realized that it first needed to understand the state of P-3C SSA's current practices with regard to the SW-CMM. After reviewing the model, the IPLT realized that the organization was already performing many of the Maturity Level 2 practices. However, many practices were not being documented using well-defined stakeholder involvement and entry and exit criteria. The leadership team agreed that the P3C SSA organization would benefit from institutionalizing the Maturity Level 3 practices by pursuing a Maturity Level 3 rating.

The P-3C SSA officially kicked off its process improvement initiative by forming a Process Improvement Group (PIG) in February 2002. The PIG consisted of members of the engineering community representing each phase of the product life cycle. PIG members accepted assignments to lead process-action teams to develop policies, processes, templates, and standards that included well-defined entry and exit criteria and stakeholder involvement. As part of the kickoff, the PIG and the IPLT attended the SEI Introduction to CMMI course.

Since the PIG did not have previous experience with TSP, several members consulted other NAVAIR teams who were familiar with TSP. They discussed the process for introducing TSP into an organization and the lessons they had learned. Eventually, the PIG elicited TSP coaching support from another NAVAIR organization. In March 2003, TSP was introduced into the P-3C SSA using the standard TSP introduction strategy. The P-3C SSA conducted an executive seminar to brief the leadership on what TSP was and the types of benefits that could be realized. Managers received the proper training and two development subteams, the Tactical Mission Software (TMS) group and Acoustics Team, were trained in PSP. The TMS subteam held its first TSP launch in May 2003. 
The process improvement effort was extremely important to senior management. To demonstrate its support, the IPLT lead attended PIG meetings, elicited feedback from the team, asked questions about current and future processes, helped facilitate the sessions, and ensured that progress was being made and that barriers to change were being removed. The IPLT lead regularly briefed upper management and the rest of the organization on the initiative. The PIG viewed senior management's involvement as a driving factor that moved the organization forward.

After planning its strategy and winning the approval of the IPLT, the PIG started 17 Process Action Teams (PATs) in June 2002, with each assigned to work on a portion of the CMMI Maturity Level 2 and 3 process areas (PAs). The PATs worked individually to establish plans that defined the required CMMI elements for each of the assigned process areas. After several months, it was determined that the PATs were ineffective because team members didn't understand their own organizational processes, which were undocumented, much less how these processes might fit together within the CMMI framework. The PIG leaders recognized that the current approach was ineffective, disbanded the PATs, and restructured the process improvement approach.

In January of 2003, the PIG formed 12 new PATs to analyze and document each phase of the product life cycle. Each PAT outlined the existing process architectures for each of its phases using flowcharts. The PATs also addressed overarching areas such as program management, configuration management, quality assurance, and training. The result was the creation of the organization's standard process architecture, which the PIG calls “The Golden Process.” This architecture is a set of well-defined processes that can be tailored to meet the needs of individual project teams. Even today, the PIG reviews all proposed changes to the Golden Process and serves as the approving authority for all change requests.

In conjunction with the process documentation effort, the organization continued to use TSP for its ongoing software development projects. In 2002, the SEI had published a milestone report titled Relating the Team Software Process (TSP) to the Capability Maturity Model $(C M M)$ for Software [Davis 02]. Based on this report, and a recommendation from the SLT that the organization consider using SW-CMM instead of CMMI, the PIG conducted an analysis to understand which process areas of the SW-CMM overlapped with their current TSP efforts and to determine where gaps existed. The group realized that TSP teams were already using the Golden Process, and that these teams' activities covered approximately $90 \%$ of the SW-CMM Maturity Level 4 key practices, so that P-3C SAA would have to close only a few gaps to obtain SW-CMM Level 4 capability.

Using the SW-CMM as a guide, the PIG lead worked with each PAT to ensure that the appropriate processes, templates, and standards were generated for each step in each product lifecycle phase. The TSP was then incorporated into the plans with the standard scripts being customized to meet the organization's needs. The PIG lead ensured that the intent of TSP methods and the SW-CMM were both preserved by reviewing the newly defined processes. The PIG also conducted a gap analysis to ensure that their implementation complied with the 
SW-CMM model. As the PATs worked to redefine processes, opportunities for improvement surfaced and were integrated into the plan.

The PIG understood that process improvement involved more than just documenting current processes, understanding and closing gaps between TSP methods and the SW-CMM, and implementing the processes on real projects. The PIG members realized that in order to make the improvements endure, the organization's culture needed to change. Everyone in the P-3C organization needed to understand what process improvement was all about and needed to become convinced that improving processes wasn’t something separate from his or her daily work, but an integral part of it. Utilizing the PIG model, the P-3C organization launched a communications campaign to keep everyone informed. New PIGs began to appear throughout the organization and posters touting the benefits of process improvement hung on the office door of every manager. They sent newsletters about process improvement, held senior management pep talks, team-building events, team training, and even picnics and a logo contest. The P-3C Process Improvement Lead, Julie Switzer, explained "People resist change because they don't understand it, they perceive it as a threat, or it's forced upon them. Involving the team, keeping them informed and encouraging them to be proactive in documenting and defining their processes helped to create a collaborative, synergistic environment. This was critical in achieving success in process improvement.”

Software development and maintenance work continued as process improvements were gradually implemented. The Acoustics Team held its first TSP launch and relaunch. Several members of the organization were trained as PSP instructors and TSP coaches.

After two years of dedicated work, new processes were in place and use of TSP methods was starting to pay dividends in improved schedule variance, increased ability to estimate costs, decreased defect density, reduced rework, faster cycle time for products, and detection of defects earlier in the development cycle [Switzer 04]. Table 1 shows some of the P-3C results.

Table 1: P-3C Process Improvement Results

\begin{tabular}{|l|l|l|l|l|}
\hline & \multicolumn{1}{|c|}{$\begin{array}{c}\text { Before } \\
\text { Process } \\
\text { Improvement }\end{array}$} & $\begin{array}{c}\text { Early Stages of } \\
\text { Process } \\
\text { Improvement }\end{array}$ & $\begin{array}{c}\text { Process } \\
\text { Improvement } \\
\text { and the } \\
\text { PSP/TSP }\end{array}$ & $\begin{array}{c}\text { Percentage } \\
\text { Change }\end{array}$ \\
\hline $\begin{array}{l}\text { Source Lines of Code } \\
\text { (SLOC) }\end{array}$ & 27,880 & 32,780 & 36,690 & $\mathrm{n} / \mathrm{a}$ \\
\hline $\begin{array}{l}\text { Productivity } \\
\text { (SLOC/hr) }\end{array}$ & 2.7 & 2.7 & 4.9 & $+81 \%$ \\
\hline
\end{tabular}




\begin{tabular}{|l|l|l|l|l|}
\hline Development defects & n/a & n/a & 105 & n/a \\
\hline Test defects & 128 & 69 & $12^{1}$ & $-91 \%$ \\
\hline Defects per KSLOC & 4.6 & 2.1 & $1^{2}$ & $-78 \%$ \\
\hline Plan Release Date & none $^{2}$ & $12 / 4 / 2001$ & $1 / 26 / 2004$ & \\
\hline Actual Release Date & & $5 / 29 / 2001$ & $2 / 5 / 2004$ & \\
\hline
\end{tabular}

In February 2004, the organization conducted what it called a "CMM snapshot assessment" to determine how the P-3C SSA was progressing and to determine its readiness for a formal assessment. The snapshot assessment identified a few weak process areas (PAs) and a SCAMPI A appraisal performed on the Measurement and Analysis and Risk Management PAs identified several small issues that the PIG and teams addressed during the next few months.

In May 2004, just 27 months after beginning their process improvement activities, the P-3C SSA organization underwent a two-week assessment and achieved Maturity Level 4.

\subsubsection{Process Improvement Timeline}

The timeline of the P-3C SSA process improvement efforts described in this case study is as follows.

- Feb. 2002 - began SW-CMM-based improvement effort, formed PIG

- Mar. 2002 - began PSP/TSP introduction

- May 2002 - launched first TSP team

- June 2002 - started PATs to develop processes

- Jan. 2003 - reformed PATs focusing on development life cycle and the SW-CMM framework

- $\quad$ May 2003 - launched second TSP team

- $\quad$ May 2004 - reached Maturity Level 4

\subsubsection{Continuing Process Improvement in the P-3C SSA Organization}

Currently, the P-3C SSA organization is transitioning from the SW-CMM to the CMMI framework. During this transition, it is revisiting and revising its mission, values, customer

$1 \quad$ Final build testing was incomplete; projected number of test defects estimated to be 37 (1 per 1 KSLOC).

2 Many requirements changes throughout the program caused excessive replanning, dates were meaningless. 
needs, and organizational goals. The PIG is conducting a CMMI gap analysis and formulating an action plan for each PAT, focusing first on the areas not specifically addressed by the SW-CMM and the improvement opportunities identified during their two-week assessment. As part of the gap analysis, the PIG is using the latest SEI technical report that maps TSP methods to the CMMI framework, Mapping TSP to CMMI [McHale 05].

\subsection{AV-8B Joint System Support Activity (China Lake, California)}

This section describes the background and approach of the AV-8B Joint System Support Activity (JSSA) organization for using TSP to decrease the amount of time spent between CMM maturity levels.

\subsubsection{Organization Background}

The organization described in this section is the AV-8B JSSA, located at China Lake, California. It provides software support for the AV-8B Harrier aircraft, shown in Figure 5, for the United States Marine Corps and its allies, Spain and Italy.

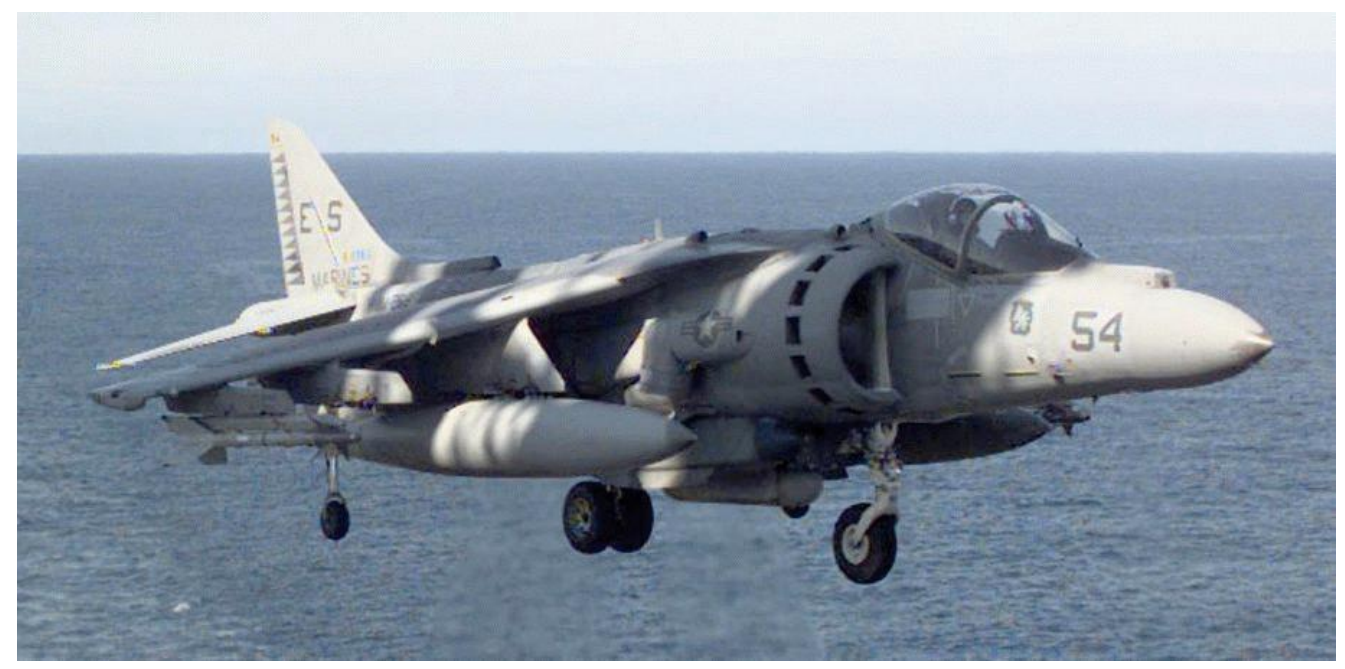

\section{Figure 5: The AV-8B Harrier Aircraft}

During the time in which the AV-8B JSSA organization began using TSP, it employed approximately 125 people. Its primary focus is on two goals: develop new software and maintain existing software.

In May 2004, the AV-8B JSSA achieved Maturity Level 4. The organization accomplished this feat in just two and a half years. 


\subsubsection{Process Improvement Approach}

The AV-8B TSP story is very similar to that of the P-3C organization. As part of the NAVAIR organization, the AV-8B organization also needed to satisfy the policy developed by the BPR, which required Maturity Level 3 or equivalent rating for all software-intensive programs and compliance with a strong recommendation to use the PSP and TSP methodologies.

The AV-8B organization also had similar process improvement goals to those identified by the P-3C SSA organization: to positively affect cost, schedule, quality, and the work environment by employing High-Performance Organization principles to improve AV-8B's leadership philosophy, culture, and business processes. To accomplish these goals it decided to use two different, but synergistic, process improvement technologies: the Earned Value Management System (EVMS) (which is also used in PSP/TSP measurements) and Capability Maturity Modeling (CMM).

The EVMS is a management technique that integrates cost, schedule, and technical performance and is based on the Department of Defense (DoD) stringent, 32-point criteria [OSD 05]. The AV-8B organization began using the EVMS in 1998. Capability milestones derived from implementing the EVMS included

- documenting organizational standard processes for activities such as negotiating commitments

- estimating, planning, and tracking all project work based on a standard work breakdown structure

- assigning and communicating responsibilities

- managing critical paths and resourced dependencies within and across projects

- taking corrective actions based on established thresholds

By May 2001, the AV-8B organization met its EVMS goals by achieving a DoD system certification [Pracchia 04].

Another significant process improvement technology the AV-8B organization used was SWCMM. It began implementing SW-CMM in March 2000 by using the traditional approach. The organization identified Software Process Improvement (SPI) goals in relation to the business goals (use of the model, attaining a maturity level, and the performance benefits). A cross-functional systems and software engineering process group (SSEPG) was formed to define the program's scope and to create an SSEPG charter. To ensure that everyone understood the foundations of SW-CMM, the SSEPG attended the Introduction to SW-CMM course. After training was complete, PATs were formed to identify and validate existing AV8B organization processes and documentation. The PATs and the SSEPG identified gaps in their current processes and what was required for a SW-CMM Maturity Level 2 rating and made adjustments to close the gaps. 
In October 2000, the AV-8B organization introduced TSP using the standard introduction strategy. The introduction included an executive seminar, manager and support staff training, and software engineer training.

The existing SW-CMM implementation was supported by the adoption of TSP as its standard software process. The TSP provided the AV-8B with a complete package of training, tools, processes, coaching, and mentoring. With TSP as its standard software process, the organization had a customizable framework with which to estimate, plan, track, communicate, and measure the quality of its software processes and work products. In addition, through assignment of standard TSP roles, responsibilities for communicating and coordinating software team activities within the larger AV-8B organization were established [Pracchia 04].

The AV-8B launched its first TSP development project for new software at the beginning of 2001, followed by the launch of a TSP project for software maintenance in mid-2002.

In May 2001, the AV-8B organization underwent a CMM-Based Appraisal for Internal Process Improvement (CBA IPI). The assessment included TSP and non-TSP projects of similar sizes. This resulted in the organization's achieving a SW-CMM Level 2 rating in just 14 months. While this assessment was officially focused on meeting Maturity Level 2 and 3 goals, the organization also created observations for the Maturity Level 4 and 5 practices to aid in understanding the effect of implementing TSP in the organization. These observations were used to help determine which SW-CMM key process areas (KPAs) were influenced by TSP and to what extent.

Initially, the EVMS and SW-CMM initiatives were not closely coordinated and the SSEPG had mixed expectations, which made process improvement efforts difficult. As a result, several changes were made to the SPI program. First, the SSEPG began executing the SPI effort as a project. It appointed an SSEPG lead who had strong project management and communication skills. The SSEPG streamlined its operations and infrastructure and developed tools for defining and improving processes and established a process configuration management process and repository. The SSEPG soon realized that there were three overlapping process improvement initiatives in place and it needed to understand the gaps and overlaps among the different projects before proceeding. To facilitate its understanding, the SSEPG obtained a copy of the SEI technical report, Relating the Team Software Process (TSP) to the Capability Maturity Model (CMM) for Software [Davis 02]. After reading the report and reviewing its assessment results, the SSEPG realized how synergistic the EVMS, SW-CMM, and TSP technologies are and that using them in conjunction with one another was important to achieving the organization's process improvement goals. The SSEPG then worked to understand and close the "gaps" between all three technologies and the organization's current practices.

In September 2002, the AV-8B organization underwent another CBA IPI and achieved a Maturity Level 4 rating 16 months after reaching Level 2. Fostering a team-oriented culture, having champions for software process improvement, having sound discipline, schedule ad- 
herence, and management support, and focusing on EVMS and TSP are factors that made success a reality.

\subsubsection{Process Improvement Timeline}

The timeline of the AV-8B process improvement efforts described in this report was as follows:

- $\quad$ March 2000 - began SW-CMM-based improvement effort

- October 2000 - began PSP/TSP introduction

- January 2001 - launched first TSP team

- $\quad$ May 2001 - reached Maturity Level 2

- June 2002 - launched second TSP team

- September 2002 - reached SW-CMM Maturity Level 4

\subsubsection{Continuing Process Improvement in the AV-8B JSSA Organization}

The AV-8B JSSA organization is currently working to address the improvement opportunities identified in its latest assessment. It is also in the process of selecting the most appropriate CMMI model representation and starting the transition to the CMMI framework. The SSEPG is using the latest SEI technical report that maps TSP methods to the CMMI framework, Mapping TSP to CMMI [McHale 05]. 


\section{Conclusion}

By using the PSP, TSP, and the CMMI framework in conjunction, organizations can jumpstart, accelerate, and better sustain their process improvement initiatives. Using the TSP methodology is a manageable way for organizations to get started with process improvement. The TSP also satisfies the majority of the CMMI project-level practices and can be readily adapted to support organizational-level practices [Davis 03, McHale 05].

However, even organizations that use this approach can encounter failures in their process improvement projects because in most organizations, it is extremely difficult to affect change. The sections below present one model of how to make change happen successfully, and how the actions of the NAVAIR organizations featured in this case study align with this model.

\subsection{Components Required for Successful Change}

Implementing process improvement or any kind of change in an organization is difficult, and many efforts fail to achieve the desired results. In his book, Strategic Organizational Change: A Practitioner's Guide for Managers and Consultants, Michael Beitler [Beitler 03] outlined a model of seven key components required for successful organizational change. These components are described as follows:

1. Involve the people who will be affected by and/or implementing the change so that they buy in and take ownership of the plan for change.

2. Communicate the need for or reasons behind the change so that the effort is seen as relevant and strategy driven.

3. Designate a champion for the change effort; a senior manager or executive is good, but a fellow employee to the majority of those involved may be even better.

4. Create a transition management team to provide emotional support and practical ideas for the organizational change.

5. Provide training in new skills, behaviors, or values to ensure competency and minimize feelings of inadequacy.

6. Bring in outside help to provide fresh perspectives and/or needed expertise.

7. Reward people for their accomplishments in implementing or adopting the desired changes.

If any of these components are missing, change is more difficult to achieve and may or may not be successfully implemented. 
Beitler's model can be used to help organizations diagnose the origin of their problems in implementing successful change or process improvement efforts, and can help in determining what types of actions are needed to correct their situations. For example, when there is resistance or refusal to change among members of the organization, it is often due to lack of buyin by the parties who must implement or actuate the change; getting these people involved and ensuring that they understand why the change is needed helps to reduce or eliminate the resistance to change. Lack of progress in implementing the plan or changes in direction may indicate lack of a champion or absence of a transition management team. When there is significant anxiety within the organization, this often means that people may lack the skills, vision, or expertise necessary to implement the change; this can be remedied by providing training or bringing in outside help. If the desired change is taking place but progress is slow or stalls, it may be that the wrong incentives (or possibly no incentives) are in place.

\subsection{Key Factors in NAVAIR's Process Improvement Success}

The P-3C SSA and AV-8B organizations successfully raised their maturity levels and met their initial business objectives in just 24 to 30 months. Analysis of their stories yields a set of success factors that are shared by both organizations. The success factors listed below are organized using the components of the Beitler model to facilitate understanding of how these factors led to the changes taking place in the two NAVAIR organizations.

\section{Involve the people who are affected by the change}

- The NAVAIR organizations treated the process improvement effort as a project with dedicated resources, and they selected project leaders with strong project management skills. Without proper and adequate resources, change will not take place.

- Involvement of the people affected by the changes in formulating and implementing the changes was one of the key success factors in the NAVAIR efforts. PATs were composed of members of the engineering community from each phase of the product life cycle; PAT members accepted assignments to recruit and lead PIGs to develop policies, processes, templates, and standards that included stakeholder involvement. Developers gained a common process vocabulary from PSP training, and then worked on TSP teams that were piloting and debugging new and updated process elements on the job.

- Leaders understood that process improvement requires a cultural change. In order for process improvement to take place and have the desired effect, the culture of the organization has to change. People must embrace the idea that process improvement is not extra work; it is how the work is to be done every day. Understanding and promoting requirements is a basic ingredient for successful process improvement. 


\section{Communicate why change is necessary and what the outcome should look like}

- NAVAIR identified its business needs. Project leaders understood why they needed to change and what the consequences would be if they didn't.

- Organizational goals and policies were established and communicated. The leadership team communicated why the process improvements needed to take place and explicitly stated its expectations for the organization.

- The NAVAIR groups began planning by first understanding their current practices, as well as identifying the gaps and overlaps between their current practices and the SWCMM and TSP. With this understanding, they were better able to understand what they needed to do, and to appropriately tailor the SW-CMM model and TSP to fit their organizational needs.

\section{Provide a champion for the change effort}

- Ensuring that there were champions at all levels of the organization who were credible to the people affected by the changes was a key factor in the NAVAIR efforts, and is a critical element in any change movement.

- The organizations had strong, visible leadership. This was another critical element, since without continued and visible support by senior leaders, most process improvement efforts fail, even if there are peer-level champions.

\section{Create a transition management team}

- Formation of cross-functional Project Action Teams (PATs), Process Improvement Groups (PIGs), and Systems and Software Engineering Process Groups (SSEPGs) provided practical ideas for improvement and were able to recognize when various approaches were not working so that the organization's approach could change.

- Team-building and communications efforts spearheaded by the PIGs helped to build awareness of and support for the change efforts; with organization-wide buy-in for the improvement efforts, implementation of the new technologies was successful.

\section{Provide training in new skills, behaviors, and values}

- Both NAVAIR organizations provided appropriate training for all participants in the change process. This training encompassed both the necessary skills for understanding and implementing the changes, as well as the skills and knowledge needed to perform the tasks required by the process itself. Process improvement teams were trained with the Introduction to CMM and Introduction to CMMI courses, and a tailored version of this material was provided for the engineers and support staff. Appropriate PSP training was provided for managers, engineers, and other support staff. Additional training was provided as needed to support the practices within each KPA.

- The two organizations developed internal PSP/TSP capabilities by training PSP instructors and TSP coaches to support the internal rollout of these technologies. By receiving 
training in the technologies to be used in the process improvement activity, employees became more valuable to the organization and increased their personal capabilities.

\section{Get outside help}

- The NAVAIR organizations utilized experts where appropriate (authorized PSP instructors, TSP coaches, and lead assessors/appraisers). Because organizations do not always have the capability or knowledge required to implement the desired changes, they should make use of experts when appropriate and advantageous.

\section{Provide rewards and communicate the benefits of changing}

- With business needs identified and communicated to organization personnel, the people in both NAVAIR groups knew why process improvements were taking place and understood what the consequences would be if the improvements were not implemented.

- NAVAIR planned for continual assessment of the status of their TSP implementation. The two organizations analyzed and published project data to ensure that they were achieving the desired results. They utilized formal and informal assessments to determine the organizations' status as measured against the SW-CMM model.

- Measurable improvements provided incentive to continue with the process improvement efforts. Understanding the problem areas and seeing measurable progress increased momentum within the organization.

\subsection{Conclusion}

By using PSP, TSP, and the CMMI framework in conjunction, organizations can achieve a quick start to process improvement, and can accelerate and better sustain process improvement initiatives already underway. Both TSP and the CMMI framework are proven-effective ways for organizations to implement successful process improvement efforts. Because TSP also satisfies the majority of the CMMI project-level practices and can be readily adapted to support organizational-level practices, better process improvement results should be expected if both technologies are implemented in a complementary fashion. 


\section{Bibliography}

URLs are valid as of the publication date of this document.

[Beitler 03]

[Chrissis 03]

[Davis 02]

[Davis 03]

[Hefley 02]

[Humphrey 96]
Beitler, Michael A. Strategic Organizational Change: A Practitioner's Guide for Managers and Consultants. San Francisco, CA: Practitioner Press International, 2003 (ISBN 0972606408).

Chrissis, Mary Beth; Konrad, Mike; \& Shrum, Sandy. CMMI ${ }^{\circledR}$ : Guidelines for Process Integration and Product Improvement. Reading, MA: Addison-Wesley Publishing Company, Inc., 2003 (ISBN 0321154967).

Davis, Noopur; \& McHale, James. Relating the Team Software Process (TSP) to the Capability Maturity Model (CMM) for Software. (CMU/SEI-2002-TR-008, ADA404970). Pittsburgh, PA: Software Engineering Institute, Carnegie Mellon University, 2002. http://www.sei.cmu.edu/publications/documents/02.reports /02tr008.html.

Davis, Noopur \& Mullaney, Julia. The Team Software Process (TSP) in Practice: A Summary of Recent Results. (CMU/SEI-2003TR-014, ADA418430). Pittsburgh, PA: Software Engineering Institute, Carnegie Mellon University, 2003.

http://www.sei.cmu.edu/publications/documents/03.reports /03tr014.html.

Hefley, W.; Pracchia, L.; \& Schwalb, J. “AV-8B's Experience Using the TSP to Accelerate SW-CMM Adoption.” CrossTalk: The Journal of Defense Software Engineering (Sept. 2002): 5-8. http://www.stsc.hill.af.mil/crosstalk/2002/09/hefley.html.

Humphrey, Watts S. Introduction to the Personal Software Process. Boston, MA: Addison-Wesley Publishing Company, Inc., 1996 (ISBN 0201548097). 
[Humphrey 99]

[Humphrey 01]

[Johnson 01]

[McAndrews 00]

[McHale 05]

[NAVAIR 04]

[OSD 05]

[Paulk 93]
Humphrey, Watts S. Introduction to the Team Software Process. Boston, MA: Addison-Wesley Publishing Company, Inc., 1999 (ISBN 020147719X).

Humphrey, Watts S. Winning with Software: An Executive Strategy. Boston, MA: Addison-Wesley Publishing Company, Inc., 2001 (ISBN 0201776391).

Johnson, J.; Boucher, K.; Connors, K.; \& Robinson, J. “Collaboration: Development \& Management — Collaborating on Project Success.” Software Magazine (February/March 2001). http://www.softwaremag.com/archive/2001feb /CollaborativeMgt.html.

McAndrews, Donald R. The Team Software Process (TSP): An Overview and Preliminary Results of Using Disciplined Practices. (CMU/SEI-2000-TR-015, ADA387260). Pittsburgh, PA: Software Engineering Institute, Carnegie Mellon University, 2000. http://www.sei.cmu.edu/publications/documents/00.reports /00tr015.html.

McHale, James \& Wall, Daniel S. Mapping TSP to CMMI. (CMU/SEI-2004-TR-014). Pittsburgh, PA: Software Engineering Institute, Carnegie Mellon University, 2005.

http://www.sei.cmu.edu/publications/documents/04.reports /04tr014.html.

NAVAIR. NAVAIR Acquisition Guide. 2004. http://akss.dau.mil/jsp/NavairAcqGuide.html.

Office of the Secretary of Defense. Earned Value Management: Integrating Cost, Schedule and Technical Performance for Project Management. http://www.acq.osd.mil/pm (2005).

Paulk, M., Curtis, B., Chrissis, M., \& Weber, C. Capability Maturity Model for Software, Version 1.1. (CMU/SEI-1993-TR-024

ADA263403). Pittsburgh, PA: Software Engineering Institute, Carnegie Mellon University, 1993.

http://www.sei.cmu.edu/publications/documents/93.reports /93.tr.024.html 
[Pracchia 04]

[Schwalb 03]

[SEI 04]

[Standish 01]

[Switzer 04]
Pracchia, L. "The AV-8B Team Learns Synergy of EVM and TSP Accelerates Software Process Improvement.” CrossTalk: The Journal of Defense Software Engineering (Jan. 2004): 20-22.

http://www.stsc.hill.af.mil/crosstalk/2004/01/0401pracchia.html.

Schwalb, J. “A Corporate-Wide TSP Program at NAVAIR.” First Annual Meeting of the TSP User Group, Pittsburgh, PA, September 29-30, 2003.

Software Engineering Institute. SW-CMM Maturity Profile March 2004 Report. Pittsburgh: Software Engineering Institute, Carnegie Mellon University, 2004.

http://www.sei.cmu.edu/appraisal-program/profile/pdf /SW-CMM/2004marSwCMM.pdf.

The Standish Group International, Inc. Extreme Chaos. http://www.standishgroup.com/sample_research/PDFpages /extreme_chaos.pdf (2001).

Switzer, J. "Integrating CMMI, TSP, and Change Management Principles to Accelerate Process Improvement." Second Annual Meeting of the TSP User Group, Pittsburgh, PA, September 27-28, 2004. Pittsburgh PA: Software Engineering Institute, Carnegie Mellon University. http://www.sei.cmu.edu/tsp/tug-2004-presentations /switzer.pdf. 


\begin{tabular}{|c|c|c|c|c|}
\hline \multicolumn{3}{|c|}{ REPORT DOCUMENTATION PAGE } & \multicolumn{2}{|c|}{$\begin{array}{l}\text { Form Approved } \\
\text { OMB No. 0704-0188 }\end{array}$} \\
\hline \multicolumn{5}{|c|}{ 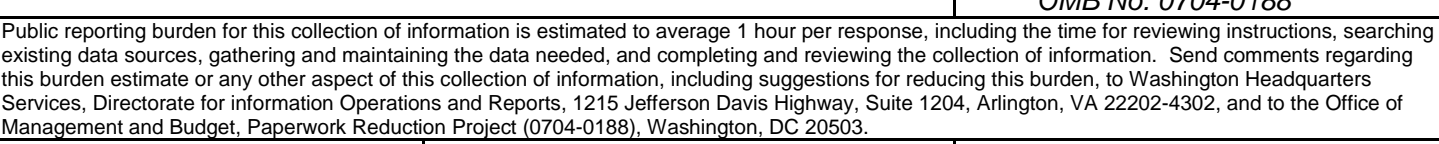 } \\
\hline $\begin{array}{l}\text { AGENCY USE ONLY } \\
\text { (Leave Blank) }\end{array}$ & \multicolumn{2}{|c|}{$\begin{array}{l}\text { 2. REPORT DATE } \\
\text { December } 2005\end{array}$} & \multicolumn{2}{|c|}{$\begin{array}{l}\text { 3. REPORT TYPE AND DATES COVERED } \\
\text { Final }\end{array}$} \\
\hline \multicolumn{3}{|c|}{$\begin{array}{l}\text { TITLE AND SUBTITLE } \\
\text { Case Study: Accelerating Process Imorovement by Integrating the } \\
\text { TSP and CMMI }\end{array}$} & \multicolumn{2}{|c|}{$\begin{array}{ll}5 . & \text { FUNDING NUMBERS } \\
& \text { FA8721-05-C-0003 }\end{array}$} \\
\hline \multicolumn{5}{|l|}{$\begin{array}{ll}\text { 6. } & \text { AUTHOR(s) } \\
& \text { Daniel S. Wall, Jame }\end{array}$} \\
\hline \multicolumn{3}{|c|}{$\begin{array}{l}\text { 7. PERFORMING ORGANIZATION NAME(S) AND ADDRESS(ES) } \\
\text { Software Engineering Institute } \\
\text { Carnegie Mellon University } \\
\text { Pittsburgh, PA } 15213\end{array}$} & \multicolumn{2}{|c|}{$\begin{array}{ll}8 . & \text { PERFORMING ORGANIZATION } \\
\text { REPORT NUMBER } \\
\text { CMUJ/SEI-2005-SR-012 }\end{array}$} \\
\hline \multicolumn{3}{|c|}{$\begin{array}{l}\text { 9. SPONSORING/MONITORING AGENCY NAME(S) AND ADDRESS(ES) } \\
\text { HQ ESC/XPK } \\
5 \text { Eglin Street } \\
\text { Hanscom AFB, MA 01731-2116 }\end{array}$} & \multicolumn{2}{|c|}{$\begin{array}{l}\text { 10. SPONSORING/MONITORING AGENCY } \\
\text { REPORT NUMBER } \\
\text { ESC-SR-2005-012 }\end{array}$} \\
\hline \multicolumn{5}{|l|}{ 11. SUPPLEMENTARY NOTES } \\
\hline \multicolumn{3}{|c|}{$\begin{array}{l}\text { 12A DISTRIBUTION/AVAILABILITY STATEMENT } \\
\text { Unclassified/Unlimited, DTIC, NTIS }\end{array}$} & \multicolumn{2}{|c|}{ 12B DISTRIBUTION CODE } \\
\hline \multicolumn{5}{|c|}{$\begin{array}{l}\text { This report describes how two U.S. Naval Air Systems Command (NAVAIR) organizations integrated the use } \\
\text { of the Software Engineering Institute's (SEI) Team Software Process SM methodology and the Capability Ma- } \\
\text { turity Modeling }{ }^{\circledR} \text { framework to progress from Maturity Level } 1 \text { to Maturity Level } 4 \text { in } 30 \text { months. This is less } \\
\text { than half of the average time it has taken other organizations to accomplish the same maturity level progres- } \\
\text { sion. This case study describes the process improvement efforts of both NAVAIR divisions and how they inte- } \\
\text { grated the two SEI technologies to accelerate process improvement within their organizations. Finally, the re- } \\
\text { port presents the key factors that allowed NAVAIR to achieve these rapid results. }\end{array}$} \\
\hline \multicolumn{3}{|c|}{$\begin{array}{l}\text { 14. SUBJECT TERMS } \\
\text { TSP, Team Software Process, PSP, Personal Software Process, } \\
\text { NAVAIR, CMMI, process improvement }\end{array}$} & \multicolumn{2}{|c|}{$\begin{array}{l}\text { 15. NUMBER OF PAGES } \\
41\end{array}$} \\
\hline \multicolumn{5}{|l|}{ 16. PRICE CODE } \\
\hline $\begin{array}{l}\text { 17. SECURITY CLASSIFICATION } \\
\text { OF REPORT } \\
\text { Unclassified }\end{array}$ & $\begin{array}{l}\text { 18. SECURITY CLASSIFICATION OF } \\
\text { THIS PAGE } \\
\text { Unclassified }\end{array}$ & $\begin{array}{l}\text { 19. SECURITY CLAS } \\
\text { ABSTRACT } \\
\text { Unclassified }\end{array}$ & SFICATION OF & $\begin{array}{l}\text { 20. LIMITATION OF ABSTRACT } \\
\text { UL }\end{array}$ \\
\hline
\end{tabular}

